\title{
Rational Choice, Personal Norms, Social Norms and Intention to Commit Resume Fraud
}

\author{
Fion L. C. MAN \\ Assistant Professor, Faculty of Business, UOW College Hong Kong, \\ 4/F, Festival Walk Tower, 80 Tat Chee Avenue, Kowloon Tong, Hong Kong Special \\ Administration Region, China \\ E-mail: fion@uow.edu.au
}

Holly H. HE

Assistant Professor, Faculty of Social Science, UOW College Hong Kong

E-mail: hollyh@uow.edu.au

Siu Kau CHEUNG (corresponding author)

Academic Registrar, UOW College Hong Kong

E-mail: skcheung@uow.edu.au

Received: Oct. 12, 2020 Accepted: Nov. 19,2020 Published: Dec. 3, 2020

doi:10.5296/ijssr.v9i1.17812 URL: http://dx.doi.org/10.5296/ijssr.v9i1.17812

\begin{abstract}
Referring to rational choice theory, theory of planned behavior, situational action theory, and model of frame selection, the study examines the effects of rational choice variables, social (subjective) norms, and personal (moral) norms on a sample of 286 associate degree graduants' intention to misrepresent information on their resumes with a view to identifying ways to curb the problem. Participants were asked to indicate their likelihood of fabricating, embellishing, and omitting information on their resumes in response to a hypothetical recruitment advertisement. Their perceived benefits/costs of resume fraud as well as the respective probabilities of occurrence, perceived social norms and personal norms were measured. Results found that only perceived benefits (but not perceived costs or the probabilities of occurrence) and personal norms (but not social norms) had direct effects on intention to commit resume fraud. The findings suggest that while job applicants are
\end{abstract}




\section{Macrothink}

International Journal of Social Science Research

ISSN 2327-5510 2021, Vol. 9, No. 1

utilitarian, their rationality is bounded, and they only use limited information in making relevant decisions. Personal norms also moderated the effect of perceived benefits on resume fraud, with effect of perceived benefits much weakened among those with higher personal norms. The results cast doubt on the use of deterrence measures to curb resume fraud. On the other hand, the importance of business ethics education is highlighted.

Keywords: resume fraud, rational choice theory, personal norms, social norms 


\section{Introduction}

In staff recruitment process, organizations invariably conduct a review of applicants' resumes to shortlist candidates before conducting interviews and other talent tests to select those most suitable for the jobs. This would pose a problem for an organization if the information included in resumes is faked. Unfortunately, the phenomenon of resume misrepresentation appears to be rampant. According to HireRight (2017), 85\% of organizations surveyed uncovered a lie or misrepresentation on a candidate's resume or job application during the screening process. In a number of self-reported surveys on application faking, ranging from $30 \%$ to $60 \%$ of participants admitted to misrepresenting educational qualifications, exaggerating their positive qualities or omitting negative qualities on their resumes (Donovan et al., 2003; McDaniel et al., 1997; Prospects, 2017). Across the Asia Pacific region, background screening conducted by employing organizations in Australia, China, Hong Kong, India, Japan, South Korea, Malaysia, Philippines and Singapore found that in 2018 an average of $15.1 \%$ of job applicants (ranged from $12.5 \%$ to $19.5 \%$ ) provided information which deviated from their education, credit, employment, professional license and criminal records (HireRight, 2019). Hong Kong's overall discrepancy rate in 2018 was $17.0 \%$, but a high percentage $(20.8 \%)$ of education screenings identified discrepancies compared to a regional average of $9.4 \%$.

Though an applicant rarely prepares a fraudulent resume with a malicious intent but to increase his or her chance of attaining a job position, it disadvantages other qualified applicants who report truthfully on their resumes. For organizations, it creates great problems by increasing hiring and training costs in case fraudsters are terminated or replaced, breeding poor performance leading to project delay when the incumbents really lack those job-related skills or experience, and subjecting the employer to legal claims related to negligent hiring (Bible, 2012; Kim, 2011). To counteract the trend, it is important that researchers identify factors related to resume misrepresentation so that effective preventive or deterrence measures can be planned.

\section{The Nature of Resume Fraud}

According to Henle et al. (2019), resume fraud can be defined as intentional misrepresentation of information on a resume in an effort to present oneself more favorably than is accurate. It can be "commissive" and "omissive" (Kim, 2011). On one hand, commissive misrepresentation introduces false information into the resume, which can be an exaggeration, stretching or distorting the truth, or a lie that is just a falsehood with no truth at all. On the other hand, omissive misrepresentation withholds information that is true but may be disadvantageous to the applicant. Through commissive and omissive acts, a job applicant can misrepresent information on the resume to create personal advantages. To be specific, resume fraud may take three forms, namely fabrication (intentionally falsifying information on resumes), embellishment (intentionally exaggerating otherwise accurate information on resumes) and omissions (intentionally excluding relevant information from resumes). It is distinguishable from unintentional mistakes and statements of trivial information, or oversights and omissions that the applicant believes are too inconsequential to be worth 
mentioning (Bible, 2012; Henle et al., 2019).

Researchers have conducted studies to examine the correlates of resume fraud with personality traits chosen as the major factors. Synyak (2014) in her study of 236 individuals found that personality traits of honesty/humility and conscientiousness were negatively correlated with fabrications, but only the latter was related to omissions. More recently, Henle et al. (2019) found that Machiavellian job applicants and those with weaker moral identities were more likely to commit resume fraud. Their findings also supported that personality traits including conscientiousness, emotional stability and agreeableness negatively correlated with the resume fraud dimensions.

Though previous studies have found that certain personality traits correlated with intention to commit resume fraud, the usefulness of the findings in curbing the problem is limited. First, it is questionable whether personality testing in selection processes really can help screen out fraudsters as the researchers proposed (e.g., Henle et al., 2019). Despite the significance of the correlations, equating Machiavellism, low emotional stability, etc. where the effect sizes were small with a heightened tendency to commit resume fraud would constitute a form of unjustified stereotyping. These traits are normal aspects of personality but not direct indications of a propensity to cheat unless when they are extreme. Second, personality traits are not easily or simply translated into a "cure" or prevention of offending in general and resume fraud in particular (Gudjonsson, 2016).

\section{Rational Choice Theory}

In this regard, theories which examine the decision-making processes of applicants contemplating misrepresenting information may provide clearer clues for intervention. Though resume fraud is not strictly a criminal act, criminological theories such as rational choice theory (RCT) (Becker, 1968; Clarke \& Cornish, 1985; Cornish \& Clarke, 1987) may shed light on why some people decide to commit resume fraud. According to Clarke (1992, 2014), though RCT may not offer a complete explanation of criminal decision-making, the theory serves to provide theoretical justification for strategies and tactics of criminal policy and crime prevention.

Rooted in classical economics and the philosophy of utilitarianism, RCT assumes that individuals, whether criminals or not, are rational and self-interested actors seeking to maximize benefits (B) (e.g., pleasure) and minimize costs (C) (e.g., sanctions), and they make choices to engage in a behavior that they perceive to be in their best interests. Despite the shared adherence to this basic principle, scholars have developed strict and modified versions of the theory (Tittle et al., 2010). The strict version proposes that an actor would attach values to the possible benefits and costs associated with a behavior, estimate the probabilities of these benefits and costs, weight the values of benefits by the probability of success (q) and the costs by the probability of being caught (p), and choose the course of action that maximizes benefits and minimizes costs. Mathematically speaking, the decision is based on the Subjective Expected Utility (SEU) from the behavior, where SEU $=\mathrm{qB}-\mathrm{pC}$ (Becker, 1968; Mehlkop \& Graeff, 2010). The strict version suggests that actors employ compensatory decision strategies which weigh and integrate all of the available and relevant information to 
estimate the SEU, and decide to engage in a behavior if its SEU is positive (Dhami \& Mandel, 2012).

While the strict version maintains that individuals calculate the rewards and costs of their actions and act to maximize their self-interest, the modified version recognizes that while people do make rational choices, they do not always engage in elaborate assessments of all the benefits and costs of various alternative courses of action or choose the optimal solution (e.g., Cornish \& Clarke, 1986). Instead, they argue that people's rationality is bounded due to limitations in human information processing, time constraints and emotions (Simon, 1957). Because of such limitations, individuals can only weigh the costs and benefits within the context of their current situations and specific experiences rather than making sophisticated calculations involving extensive computing. More often, the actual reasoning may mean just some rudimentary cognitive processing of pros and cons and eventually a person may opt for a solution that is satisfactory instead of optimal (Cornish \& Clarke, 1989; Van Gelder, 2013).

Rational choice theory has been widely used to explain a broad range of deviant behaviors such as sexual assault (Bachman et al., 1992), theft and violence (Matsueda et al., 2006), and digital piracy (Higgins, 2007). Despite the promising findings, there have been criticisms that RCT fails to incorporate the emotional and moral aspects of criminal behaviors (e.g., Walters, 2015).

\section{Emotions vs. Rational Choice}

The significance of the emotional aspects of criminal behaviors is highlighted in a number of empirical studies. De Haan and Vos (2003) found that many cases of robbery were committed without planned intentions but were perpetrated on impulsivity. In the study by Cromwell et al. (2003) on shoplifting, more than $20 \%$ of the interviewed offenders gave accounts that their offending behavior was motivated by feelings such as stress, thrill and impulsivity. These authors questioned the assumption of RCT that perpetrators make a priori choices and decisions in all cases and act to achieve an explicit aim. They contended that RCT overestimates the importance of rationality in these activities and underestimates the relevance of emotions and impulsivity.

Despite the validity of these comments, RCT does seem to have relevance to intention to misrepresent information on resumes. Van Gelder (2013) put forward a hot/cool perspective of criminal decision making which involves two qualitatively distinct modes of mental processing that guide behaviors. Individuals in the hot mode react in a more intuitive manner, responding to situational characteristics such as temporal urgency and their controllability while taking little account of probabilities or outcomes. When triggered by external stimuli or under urgency, the hot mode prevails, and the individual becomes insensitive to the input variables of rational choice models. The resultant behavior can deviate from or even go against what would be a beneficial course of action in terms of perceived utility and long-term consequences. On the other hand, the cool, cognitive mode, which is responsible for weighing costs against benefits and assessing long-term consequences of decisions, is sensitive to considerations such as probabilities and extra-legal costs such as anticipated guilt and social disapproval. The cool mode therefore functions much in accordance with the 
deliberation assumed by rational choice models of offending. Whether the hot or the cool mode prevails depends on the context. As Shover and Hochstetler (2005) explained, the contexts that white-collar criminals operate differ from those of street offenders. When applicants prepare their resumes for job application, they operate in a context where there is a longer time perspective allowing them to exercise their cool, cognitive mode. They can carefully weigh costs against benefits and decide if misrepresenting information is to their advantage much in line with the assumptions of RCT (Shover \& Hochstetler, 2005). Impulsivity and feelings such as anger, excitement and frustration should play a minimal role, supporting the application of RCT in explaining decisions to commit resume fraud.

\section{Subjective Norms and Personal Norms}

Apart from the emotional aspects, critics also pointed out that RCT neglects the moral belief system of an individual in decision-making (Walters, 2015). From a sociological point of view, Etzioni (1988) challenged the assumption of the neo-classical paradigm that assumes people are by nature individualistic, rational and utilitarian. He emphasized that people do not just act on the basis of their selfish interests, but also take into account the norms and interests of the community to which they belong when making decisions.

In this regard, the concept of subjective norms as proposed by the theory of reasoned action (Ajzen \& Fishbein, 1970) or its extension the theory of planned behavior (TPB) (Ajzen, 1985, 1991 ) is instructive. According to TPB, a person's actual behavior is directly influenced by his or her behavioral intention, which in turn is jointly shaped by three factors, namely (1) attitudes toward the behavior, i.e., beliefs about a behavior or its consequences; (2) subjective norms, i.e., the extent to which the social milieu approves or not the particular behavior; and (3) perceived behavioral control, i.e., the perceived difficulty or ease of performing the behavior. Subjective norms are those which people know about what others think about the behavior. Through understanding the normative expectations of others, the person perceives social pressure to undertake or relinquish the behavior, which may affect his or her motivation to comply with these expectations (Skrzypiec, 2017; Wenzel, 2004). In studies examining the relevance of these factors to various criminal behaviors and offences such as digital piracy (Yoon, 2010), use of pirated software (Liao et al., 2010), cheating (Stone et al., 2009), aggression (Zinatmotlagh et al., 2013), and plagiarism (Curtis et al., 2018), subjective norms exerted a direct effect on top of attitudes toward the behavior on intention to commit a crime. As Mehlkop and Graeff (2020) and Wenzel (2004) explained, other people may decide to show their contempt for, withhold social support from, or even end the relationship with the person whose behavior deviated from their norms. Thus, subjective norms can add social costs to the behavior and strengthen the overall deterrence effect.

While TPB recognizes the importance of subjective norms (also known as "social norms"), the concept of moral or personal norms does not have a place in the model. According to Doran and Larsen (2016), Schwartz (1977) and Wenzel (2004), personal norms reflect moral standards acquired through the internalization of social norms, and are experienced as expectations, sanctions and obligations that are anchored in the self. This is achieved through a process of self-categorization or identification with the group to which people attribute the 
norms. They differ from subjective or social norms, which have not yet been internalized but remain external to the person. In an early empirical study, Ajzen and Fishbein (1969) examined motivation to comply with personal norms as one of the factors but deleted it from the analyses because it did not improve the prediction of behavioral intention. Later, the concept of personal norm was dropped from the model because of its high correlation with intention, leading to the authors' conclusion that personal norm was just an alternative measure for behavioral intention (Ajzen \& Fishbein, 1980).

The omission of personal norms may be due to a misunderstanding of their role in the prediction of criminal behavior. According to Schwartz (1977), personal norms, when activated, influence a behavior. This occurs when the person is aware of the consequences of the behavior for the welfare of others and at least some responsibility for these consequences can be ascribed to himself or herself. Thus, a person contemplating a criminal act is likely to have his or her personal norms activated, generating guilty conscience or cognitive dissonance due to potential norm violation. As Paternoster and Simpson (1996) emphasized, such moral inhibitions are deontological and not based on consequences of the behavior. Actions which violate one's personal norms may be immediately removed from consideration despite the potential benefits they may bring.

This notion has been incorporated in two recent formulations of human behaviors, namely Situational Action Theory (SAT) (Wikström, 2004) and Model of Frame Selection (MFS) (Kroneberg et al., 2010). In SAT, Wikström (2004) argued that a person's propensity to choose a certain behavior as an action alternative is dependent on the person's morality (moral rules and emotions of shame and guilt) and the person's ability to exercise self-control. Because of his or her internalized personal norms, an actor may totally rule out fraud as an action alternative. Similarly, MFS argues that cost-benefit calculation is just one consideration among others underlying an individual behavior (Kroneberg et al., 2010). When a personal norm has been strongly internalized and the normative framing of the situation is so intact that the actor cannot escape the norm's demand for compliance, the norm would be activated strong enough to inhibit deliberation of other alternatives. Both formulations suggest that personal norms may moderate the effect of expected utility on the intention to commit resume fraud. Only those who do not feel bound by such personal norms weigh the costs and benefits and develop an intention to commit resume fraud. For those with strongly internalized personal norms against fraud, they will not be incentivized to misrepresent information despite the expected utility. Even if they do contemplate doing so, they may be influenced by the guilt or shame that comes from acting against their principles, thus undermining the effect of cost/benefit consideration on the intention (Tittle et al., 2010).

\section{The Present Study}

The present study examines the effects of rational choice considerations, social norms and personal norms on the intention to commit resume fraud among our associate degree students. Regarding rational choice considerations, we investigate competing versions of RCT to predict the intention to misrepresent information. According to the strict version, a perfect decision whether to misrepresent information should be based on subjective utility value 
(SEU) of the behavior, i.e., SEU $=\mathrm{qB}-\mathrm{pC}$. By contrast, the modified form suggests that such complex calculation is in most cases not possible, especially because people lack information about the benefits, costs and the probabilities of their occurrence. In these circumstances, people have a tendency to use heuristics or perform attribute substitution, and the decision-making process is subject to biases such as availability and representativeness biases (Kahneman \& Frederick, 2004; Shah \& Oppenheimer, 2008). A simple measure of the perceived benefits or costs would better predict the intention to misrepresent information than a measure that interactively combines the perceived benefits with the subjective probability of the benefits. The present study compares three models (Model 1 to 3 ) of RCT. The first model, based on the modified version, includes the benefits, costs and their probabilities of occurrence as four separate predictors. The second model involves slightly more sophisticated calculation in which the benefits and costs, each weighted by the respective probability, were entered as two predictors in the equation. The third model is based on the strict version of RCT using $\mathrm{SEU}(\mathrm{qB}-\mathrm{pC})$ as the variable to predict the intention to misrepresent information on resumes.

Second, the study examines the role of social norms and personal norms on the intention to misrepresent information. According to TPB, SAT and MFS, both social and personal norms prohibiting misrepresentation are hypothesized to be negatively related to the intention to misrepresent information, and are expected to exert an independent effect on top of the rational choice variables. In this study, we enter social norms and personal norms into the three regression models consisting of RCT variables. Then, we compare the effects of different combinations of the variables on the intention to misrepresent information on resume.

Third, the study examines the moderating effect of personal norms on rational choice variables in predicting intention to misrepresent information. Both SAT and MFS argue that personal norms can lead actors to disregard instrumental incentives to commit a deviant behavior. The more strongly such norms have been internalized, the smaller the effects of cost and benefit consideration are. In the context of resume fraud, those who have internalized the norms prohibiting misrepresenting information will spontaneously refrain from contemplating the action without considering its benefits. Only the subgroup of actors with relatively weak internalization would take advantage of deceptive actions. Theoretically, we hypothesize that the personal norms moderate the effects of rational choice variables on the dependent variable. In statistical terms, we expect a significant interaction between rational choice variables and personal norms in the prediction of intention to misrepresent information. Accordingly, Model 4 and 5 are established (based on the data analysis of Model 1 to 3) to assess how personal norms may moderate rational considerations; while Model 6 and 7 are built to further examine how the rational choice variables affect the intention to misrepresent information among participants with low and high levels of internalized personal norms, respectively. 


\section{Materials and Methods}

\subsection{Sample}

Respondents were final year students studying associate degree programs in a tertiary institution in Hong Kong. The respondents were asked to fill in the research questionnaire in class. A total of 300 questionnaires were collected, and 286 valid and complete samples were obtained. Among them, 121 were men and 156 were woman. Their age ranged from 21 to 24 (median age $=22$ years). More students studied in a program in the Faculty of Business $(n=$ $162,56.6 \%$ ), whereas 124 students $(43.4 \%)$ studied in a program in the Faculty of Social Sciences.

\subsection{Measures}

Respondents filled in a self-administered questionnaire that presented a hypothetical recruitment advertisement for an assistant project officer offering attractive remuneration package and career prospect. The advertisement stated certain job requirements (such as Proficiency in MS Office; Good command of Putonghua and English; Chinese typing using root-based input method, etc.) and desirable characteristics (such as part-time job experience; meaningful volunteer experience; travel experience to countries beyond China, no academic misconduct during secondary or college education, etc.), which students were unlikely to meet all. After reading the advertisement, respondents were asked to indicate their responses to 27 statements assessing their intention to misrepresent information on resume, perceived benefits and the probability of success, perceived severity of penalty and the probability of detection, personal norms and social norms. The scenario method is commonly used in social and psychological research on deviant behaviors (e.g., Haar \& Wikström, 2010; Tibbets \& Myers, 1999). Though it can be argued that an expressed intention to commit an act may not imply actual performance, research on TPA has found a high correlation between intentions and actual performance of deviant behavior (e.g., Norman, 2011; Zinatmotlagh et al., 2013).

\subsubsection{Intention to Misrepresent Information on Resume}

Respondents were asked to imagine that they were to apply for the job and rate the possibility on a 7-point scale from 1 (highly unlikely) to 7 (highly likely) that they might fabricate (two items: "Claim experience that you do not actually have"; "Make up information about you that are actually false"), exaggerate (two items: "Describe yourself in a way that is better than what you truly are"; "Exaggerate your experience or abilities") and omit information (two items: "Omit information that makes you look not so positive"; "Leave off information that might hurt your chances of getting the job") in their application.

\subsubsection{Perceived Benefits}

Respondents were asked to show their degree of agreement on a 7-point scale from 1 (strongly disagree) to 7 (strongly agree) with five statements including "If I claim relevant experience that I actually do not have, I would be given preference for the position", "If I omit my bad records, I would have a greater chance to be selected for an interview", etc. Cronbach's alpha for the 5-item scale was .70. 


\subsubsection{Probability of Success}

Respondents were asked to estimate on a 7-point scale from 1 (highly unlikely) to 7 (highly likely) the likelihood that he or she was able to construct a resume with embellishment that is taken as true by the human resources officer of the organization.

\subsubsection{Perceived Severity of Penalty}

Respondents were asked to show their degree of agreement on a 7-point scale with five statements including "There may be legal consequences if any inaccurate information on my resume is discovered", "If any inaccurate information on my resume is discovered, I may be blacklisted by the company", "If any inaccurate information on my resume is discovered, I may be fired later even if I am given the job offer", etc. Cronbach's alpha for the 5-item scale was .80 .

\subsubsection{Probability of Detection}

Respondents were asked to estimate on a 7-point scale the probability that any exaggeration of his or her strengths or omission of negative information about him or her would be discovered by the human resources officer of the organization.

\subsubsection{Personal Norms}

Respondents were asked to show their degree of agreement on a 7-point scale with five statements including "I would feel guilty if I misrepresent information on my resume", "It would be morally wrong for me to misrepresent information on my resumes", "I would feel okay if I distort information a little bit on my resume in order to get the job" (reverse scored), etc. Cronbach's alpha for the 5-item scale was .77.

\subsubsection{Social Norms}

Respondents were asked to show their degree of agreement on a 7-point scale with three statements "Most people who are important to me would look down on me if they know I exaggerate my strengths or hide negative information about me on my resume", "No one who is important to me thinks it is okay if I exaggerate my strengths or hide negative information about me on my resume", etc. Cronbach's alpha for the 3-item scale was .67.

\subsubsection{Control Variables}

Five control variables will be included in this study: (1) academic program of study, (2) grade point average (GPA), (3) religion, (4) place of having secondary education, and (5) gender.

\subsection{Results}

Table 1 displays the means and standard deviations of the major variables. T-test showed that men had higher intention to misrepresent information on resume than women, $t(284)=1.99$, $p<.05$. However, there was no difference in the intention to misrepresent information between the students of the two faculties, $t(283)=.201, p=.84$, places where students had their secondary education, $F(2,282)=1.34, p=.264$, and religion, $F(4,273)=1.828, p$ $=.124$. Results of Spearman correlation indicated no significant association between 
intention to misrepresent information on resume and GPA, $r s(286)=.02, p=.69$.

Table 1. Means and standard deviations of variables

\begin{tabular}{llll}
\hline Variables & Range & Mean & Std. Deviation \\
\hline Intention to misrepresent information on resume (I) & $6-42$ & 21.74 & 6.40 \\
Perceived benefits (B) & $5-35$ & 20.29 & 5.28 \\
Probability of success (q) & $1-7$ & 4.13 & 1.46 \\
Perceived severity of penalty (C) & $5-35$ & 27.35 & 5.43 \\
Probability of detection (p) & $1-7$ & 4.39 & 1.30 \\
Social norms (SN) & $4-28$ & 19.27 & 4.83 \\
Personal norms (PN) & $4-28$ & 19.26 & 4.53 \\
\hline
\end{tabular}

Table 2 shows the Pearson correlations between the dependent variable (I) and the other variables. All but one - the probability of detection - are significant and in the expected directions.

Table 2. Bivariate correlations between intention to misrepresent information on resume and other variables included in the analyses

\begin{tabular}{lllllll}
\hline & $\mathrm{I}$ & $\mathrm{B}$ & $\mathrm{q}$ & $\mathrm{C}$ & $\mathrm{p}$ & $\mathrm{SN}$ \\
\hline $\begin{array}{l}\text { Intention to misrepresent } \\
\text { information on resume (I) }\end{array}$ & 1.000 & & & & & \\
Perceived benefits (B) & $.437^{* *}$ & 1.000 & & & & \\
Probability of success (q) & $.320^{* *}$ & .011 & 1.000 & & & \\
Perceived severity of penalty (C) & $-.213^{* *}$ & $.332^{* *}$ & $-.124^{*}$ & 1.000 & & \\
Probability of detection (p) & -.094 & -.054 & $.261^{* *}$ & .003 & 1.000 & \\
Social norms (SN) & $-.350^{* *}$ & $-.160^{* *}$ & $.610^{* *}$ & $-.204^{* *}$ & $.399^{* *}$ & 1.000 \\
Personal norms (PN) & $-.561^{* *}$ & $-.408^{* *}$ & $.483^{* *}$ & $-.393^{* *}$ & $.193^{* *}$ & $.587^{* *}$ \\
\hline
\end{tabular}

Note. ${ }^{*} p<.05 ; * * p<.01$.

To test the hypotheses, three models of multiple regression analyses on intention to misrepresent information on resume were conducted. Gender was the only demographic variable entered as covariate in the analyses, in consideration of the T-test result on gender difference. Model 1 in Table 3 shows the results of analysis that treats the parameters B, q, C and $\mathrm{p}$ as equal. This model represents a situation in which an individual uses mental shortcuts and considers the parameters selectively when making the decision. In Model 2, the product terms $\mathrm{qB}$ and $\mathrm{pC}$ were used instead, which came closer to the idea of rational choice theory. Here, the model assumes $q$ and $p$ serve as weights rather than independent predictors, and an individual has to perform deliberate calculation when making the decision. Model 3, 
corresponding to the strict version of $\mathrm{RCT}$, used the term $\mathrm{qB}-\mathrm{pC}$ as the predictor. The model assumes a rational model of decision-making in which intention to misrepresent information is higher if SEU is positive and high. In all three models, social norms (SN) and personal norms (PN) were entered as additional predictors. With gender, SN and PN all included as covariates in the three models, a comparison of the overall coefficients of determination $\left(R^{2}\right)$ would reveal the relative predictive powers of the three combinations of rational choice variables.

The $R^{2}$ in the three models were $.373, .319$ and .327 respectively, all being significant at .001 level. However, obviously Model 1 is the most powerful among the three. In that model, after controlling for the effect of gender, only perceived benefit $(\beta=.23, p<.001)$ and personal norms $(\beta=-.405, p<.001)$ had significant effects on the dependent variable. On the other hand, in Model 2 and Model 3, though personal norms remained a significant predictor, the contributions of the other variables were all insignificant. In other words, respondents' intention to misrepresent information on their resumes did not seem to be based on a calculation of benefits and costs as assumed by the strict/hard versions of rational choice theory. Similarly, in all three models, the zero-order relation of social norms and misrepresentation ( $r=-.35$ ) was turned insignificant, suggesting its effect might have been mediated by personal norms and perceived benefit.

Table 3. Regression analyses on intention to misrepresent information on resume

\begin{tabular}{|c|c|c|c|c|c|c|c|c|c|}
\hline & Model 1 & & & Model 2 & & & Model 3 & & \\
\hline Variable & $\mathrm{B}$ & SE & $\beta$ & $\mathrm{B}$ & SE & $\beta$ & $\mathrm{B}$ & $\mathrm{SE}$ & $\beta$ \\
\hline Intercept & 27.729 & 2.983 & & 23.743 & 1.063 & & 36.660 & 2.183 & \\
\hline Gender & -0.727 & 0.635 & -.056 & -1.254 & 0.642 & -.097 & -1.005 & 0.648 & -.078 \\
\hline Benefits (B) & 0.279 & 0.068 & $.231 * * *$ & & & & & & \\
\hline $\begin{array}{l}\text { Probability of } \\
\text { success (q) }\end{array}$ & 0.247 & 0.233 & .057 & & & & & & \\
\hline Costs (C) & 0.054 & 0.075 & .046 & & & & & & \\
\hline $\begin{array}{l}\text { Probability of } \\
\text { detection (p) }\end{array}$ & 0.122 & 0.257 & .025 & & & & & & \\
\hline$q \times B$ & & & & 0.013 & 0.037 & .018 & & & \\
\hline $\mathrm{p} \times \mathrm{C}$ & & & & -0.013 & 0.039 & -.017 & & & \\
\hline $\operatorname{SEU}(\mathrm{qB}-\mathrm{pC})$ & & & & & & & 0.012 & 0.006 & .128 \\
\hline $\begin{array}{l}\text { Social norms } \\
\text { (SN) }\end{array}$ & -0.130 & 0.093 & -.098 & -0.057 & 0.081 & -.043 & 0.007 & 0.086 & .005 \\
\hline $\begin{array}{l}\text { Personal norms } \\
(\mathrm{PN})\end{array}$ & -0.572 & 0.097 & $-.405 * * *$ & -0.740 & 0.087 & $-.524 * * *$ & -0.674 & 0.093 & $-.478 * * *$ \\
\hline$R^{2}$ & .373 & & & .319 & & & .327 & & \\
\hline $\mathrm{F}$ & $23.477 * * *$ & & & $25.997 * * *$ & & & $33.891 * * *$ & & \\
\hline
\end{tabular}

Note. $* p<.05 ; * * p<.01 ; * * * p<.001$. 
To test the hypothesis that personal norms moderate the effect of rational considerations on intention to misrepresent information, Model 4 included gender as the covariate, perceived benefits as the independent variable, and personal norms as the moderator, and in Model 5, the product term between the latter two variables was added. The other variables including perceived severity of penalty, the probabilities of success and detection, and social norms were omitted from the analyses given their insignificant relations with the dependent variable in Model 1. Following Dawson's (2014) recommendations for regression analyses to test interactions, the main variables were first mean-centered before calculating the interaction term to reduce the risk of multicollinearity. As shown in Table 4, both perceived benefits and personal norms showed the predicted relationships with intention to misrepresent information. The higher the respondents perceived the benefits of misrepresentation and the less the respondents were committed to the relevant personal norms, the more likely they were to misrepresent information on their resumes. In Model 5, the addition of the two-way interaction term significantly contributed to an increase in variance of intention explained, $\Delta R^{2}=.009, p=.047$, supporting that personal norms moderate the effect of perceived benefits on intention to misrepresent information.

To test the hypothesis that the effects of perceived benefits on intention are stronger when commitment to relevant personal norms is lower, the sample was divided into two groups, namely weaker personal norms group (personal norms $\leq 16, n=80$ ) and stronger personal norms group (personal norms $>16, n=206$ ), and the effects of perceived benefits on intention were again assessed. Results of Model 6 and Model 7 showed that perceived benefits had a stronger relationship with intention $(\beta=.503, p<.0001)$ for the weaker personal norms group than for the stronger personal norms group $(\beta=.273, p<.0001)$. The total variance explained by perceived benefits in the weaker personal norms group $\left(R^{2}=\right.$ 0.259 ) was also much larger than the one in the stronger personal norms group $\left(R^{2}=.086\right)$, suggesting that perceived benefits exerted greater effects on intention to misrepresent information for those with weaker personal norms. 


\section{Macrothink}

International Journal of Social Science Research

ISSN 2327-5510

2021, Vol. 9, No. 1

Table 4. Regression analyses to test moderating effect of personal norms on perceived benefits to predict misrepresentation intention

\begin{tabular}{|c|c|c|c|c|c|c|c|c|c|c|c|c|}
\hline \multirow[b]{2}{*}{ Variable } & \multicolumn{3}{|c|}{$\begin{array}{l}\text { Model } 4 \\
(N=286)\end{array}$} & \multicolumn{3}{|c|}{$\begin{array}{l}\text { Model } 5 \\
(N=286)\end{array}$} & \multicolumn{3}{|c|}{$\begin{array}{l}\text { Model } 6 \\
(\mathrm{PN} \leq 16, n=80)\end{array}$} & \multicolumn{3}{|c|}{$\begin{array}{l}\text { Model } 7 \\
(\mathrm{PN}>16, n=206)\end{array}$} \\
\hline & B & SE & $\beta$ & B & $\mathrm{SE}$ & $\beta$ & $\mathrm{B}$ & SE & $\beta$ & B & SE & $\beta$ \\
\hline Intercept & 22.836 & 1.025 & & 28.659 & 2.610 & & 14.275 & 3.240 & & 15.19 & 2.17 & \\
\hline Gender & -0.692 & 0.621 & -.054 & -0.755 & 0.619 & -.058 & -0.552 & 1.086 & -.050 & -0.763 & 0.792 & -.066 \\
\hline Benefits & 0.291 & 0.064 & $.240 * * *$ & 0.300 & 0.064 & $.247 * * *$ & 0.573 & 0.112 & $.503 * * *$ & 0.306 & 0.077 & $.273^{* * *}$ \\
\hline $\begin{array}{l}\text { Personal } \\
\text { norms (PN) }\end{array}$ & \multicolumn{12}{|c|}{ norms (PN) } \\
\hline Interaction: & & & & -0.021 & 0.011 & $-.096^{*}$ & & & & & & \\
\hline \multicolumn{13}{|l|}{$\mathrm{B} \times \mathrm{PN}$} \\
\hline$R^{2}$ & \multicolumn{3}{|l|}{.369} & \multicolumn{3}{|l|}{.378} & \multicolumn{3}{|l|}{.259} & \multicolumn{3}{|l|}{.086} \\
\hline $\mathrm{F}$ & \multirow{3}{*}{\multicolumn{3}{|c|}{$55.074 * * *$}} & \multicolumn{3}{|c|}{$42.733^{* * *}$} & \multicolumn{3}{|c|}{$13.49^{* * *}$} & \multicolumn{3}{|c|}{$9.589 * * *$} \\
\hline$\Delta R^{2}$ & & & & \multicolumn{3}{|l|}{.009} & & & & & & \\
\hline$\Delta F$ & & & & $3.971^{*}$ & & & & & & & & \\
\hline
\end{tabular}

\subsection{Discussion}

The study examines the interplay of rational choice considerations, social norms and personal norms on the intention to misrepresent information on resumes. Regarding rational choice theory, we compare the relative effectiveness of three models consisting of different combinations of rational choice variables. Model 1 represents the modified form of RCT with perceived benefits, probability of success, perceived severity of penalty and probability of detection as four individual elements; Model 2 uses perceived benefits and perceived severity of penalty as two elements, each weighted by its respective probability; and Model 3, the strict form of RCT, uses subjectively expected utility from misrepresenting information on resumes as the independent variable. Though Model 1 is considered absurd by the upholders of strict rationality (Dahlbäck, 2003; Mehlkop \& Graeff, 2010), the findings of this study are more consistent with its predictions. When applicants contemplate exaggerating or omitting information on their resumes, their decisions are less likely based on a sophisticated calculation of benefits/costs of misrepresenting information weighted by their respective probabilities. Instead, individuals mainly consider perceived benefits, leaving out probability of its success, perceived severity of penalty, and probability of detection. Though the results are in line with the utilitarian notion that people are egoists acting to achieve their own self-interests, they suggest that individuals often lack the rational capacity to perform calculations and make utility-maximizing decisions as the strict version of RCT has assumed. On the contrary, as the idea of bounded rationality proposes, people may use heuristics or perform attribute substitution, selectively attending to the benefits that misrepresentation of information may bring and ignore the probability of its occurrence and the costs as associated.

Among the rational choice variables, the study reveals that perceived penalty is not a 
significant predictor of the behavioral intention. This is in line with the results of some previous studies showing that perceived benefits appear to have greater effects than losses on people's intention to engage in deviant behavior (Dhami \& Mandel, 2012; Parsons et al., 1997, 2000). It is probably due to the fact that, unlike criminal offences where formal and informal sanctions are widely known, the costs related to falsified information being detected by an employing organization are only long-term and vaguely perceived. Even those who are aware of such costs may not experience strong or prominent fear emotions that would inhibit the intention to commit resume fraud. On the other hand, employers often present job-related benefits and career prospects in job advertisements to attract potential applications. Such information may draw applicants' attention to the benefits that misrepresenting information may bring, making the benefits immediate and easier to be envisaged.

The study also examines the constructs of social norms and personal norms and their relations to the intention to misrepresent information. The distinction between social and personal norms was put forward by Schwartz (1977) in his norm-activation theory. While social norms (or subjective norms) in TPB refer to the perceived social pressure to perform or not to perform the behavior in question, personal norms (or moral norms) reflect one's commitment to internalized values and are experienced as personal obligations to engage or not to engage in the behavior. The results of Models 1 to 3 all show that commitment to personal norms is highly relevant to the decision to misrepresent information, with its effect being even greater than that of perceived benefits. Those who are more committed to personal norms against misrepresenting information are less likely to commit the behavior. In contrast, social norms appear to be of lower predictive value compared to personal norms. When social norms and personal norms are examined simultaneously, the relation of social norms to the intention of misrepresenting information is reduced to non-significance. This pattern concurs with several previous studies on environmental behavior which reported a strong attenuation of the correlation between perceived social norms and behavior when personal norms were controlled, despite a significant and positive bivariate correlation (Biel \& Thoegersen, 2007; Black et al., 1985; Botetzagias et al., 2015; Hopper \& Nielsen, 1991). Similarly, a few studies on criminal behaviors among young people found that moral norms mediate the effects of peer rejection on deviant behaviors (Foglia, 1997; Fontaine et al., 2012). In fact, as a number of scholars have argued, the social milieu influences an individual to commit a behavior not so much through social pressure but rather through the construction of personal moral norms (e.g., Fornara et al., 2011; White et al., 2009). In other words, personal norms serve as a mediator of social norms over behavioral intention. When a person expects negative reactions from his or her significant others, the person is likely to develop the internal moral evaluation that the behavior is wrong, and the behavior is thus inhibited. The findings thus pose challenges to the Theory of Planned Behavior (Ajzen \& Fishbein, 1970), which accords social norms a higher conceptual priority to personal norms. As the findings of this and previous studies show, personal norms appear to be a more proximal variable exerting direct effect on behavioral intention than social norms.

The study also examines the hypothesis that personal norms moderate the effect of perceived benefits and costs on behavioral intention. As results of Model 5 indicate, apart from its direct 
effect, the interaction term between personal norms and perceived benefits adds significant contribution to the variance of intention to misrepresent information on resumes, indicating a moderating effect of personal norms on perceived benefits. Model 6 shows that among those whose commitment to relevant norms is lower, perceived benefits have a strong and significant effect on the intention to misrepresent information. On the other hand, as revealed in Model 7, the effect of perceived benefits among those holding a higher commitment to relevant norms is much reduced. These findings are in line with previous studies on a number of offences which show the moderating effects of morality on perceived costs and benefits (e.g., Bachman et al., 1992; Wenzel, 2004). The findings provide support to SAT and MFS, which contend that the effects of perceived costs and benefits would be smaller for those who have internalized relevant personal norms. However, despite the support for SAT and MFS, it should be noted that the effects of perceived benefits on intention to misrepresent information on resumes are significant both for individuals with higher and lower levels of personal norms though to different degrees. Perhaps, unlike many other criminal offences, applicants are likely to consider resume fraud only a mild misdeed. Therefore, despite an awareness of the norms at the cognitive level, the moral emotions such as guilt and shame aroused are not strong enough to totally inhibit the enticement of perceived benefits. Even for individuals whose commitment to personal norms is higher, perception of benefits still prompts them to misrepresent information on resumes.

\subsection{Implications}

The findings have implications for preventive or deterrence measures against resume fraud. According to deterrence theory (Beccaria, 1963; Wright, 2010), penalty may exert deterrence effect on resume fraud in two ways. First, by increasing the certainty of punishment, job applicants contemplating resume fraud may be deterred by the risk of being detected and penalized. Second, the severity of punishment may affect behavioral intention if job applicants weigh the consequences of their actions and conclude that the risks of penalty are too severe. It is not the objective nature of the situation itself that affects the decision, but rather it is the individuals' subjective perceptions of the risks and costs associated with the behavior in a specific situation that count (Pogarsky et al., 2004). Based on the theory, career advisors have attempted to educate and inform job applicants of legal ramifications and other consequences of resume fraud. Some employing organizations also put up warnings on the consequences with a view to deterring applicants from misrepresenting information on their resumes. However, results of this study show that job applicants are neither sensitive to probability nor severity of penalty expectation, casting doubt on the effectiveness of such approaches. Although applicants may be aware of the potential penalties and even consider them probable, they may still intend to commit resume fraud when there are perceived benefits in doing so.

On the other hand, this study shows that a person's commitment to personal norms is the critical factor to curb resume fraud. When tempted to fabricate or embellish one's resume to gain advantage in job application, one's moral principles and standards constitute the major if not the only force to avert the unethical behavior. Especially for graduates who have not yet entered the workforce, the responsibility to inculcate the moral principles falls on the 
shoulders of the colleges and universities rather than the employers. Pedagogically, in business education, students should be inculcated with ethical principles and standards and helped to integrate them in their moral systems. However, it looks impossible to bring up for discussion all the miscellaneous ethics-related business and work-related behaviors in a curriculum. Compared to topics such as corporate social responsibility, bribery and corruption, race discrimination, sexual harassment and embezzlement, resume fraud in job application may look too trivial to be included as one topic in the curriculum. Instead of examining the miscellaneous ethical issues one by one, a more effective approach should be on developing students' general ethical reasoning skills so that they can judge whether specific behaviors are right or wrong even though there is no rule or code of ethics governing them.

\subsection{Limitations and Directions for Future Research}

Although the present study provides some interesting results for theoretical understanding of resume fraud and practical implications, there are limitations that need to be considered. First, though the findings of the study suggest that job applicants' intention to commit resume fraud is not so much affected by cost considerations, we must note that this may be due to the absence of such warnings in the hypothetical advertisement in the survey instrument, making the cost information less salient than the benefit information. Since human cognitive processes are subject to availability bias, it is possible that job applicants would be more sensitive to the negative consequences if such warnings were highlighted in the advertisement. Future research using a hypothetical advertisement with a warning against resume fraud is warranted.

Second, the insignificance of social norms to predict resume fraud intention may be due to an incomplete conception of the variable in the context of Hong Kong. In this study, we assume that job applicants generally expect disapproval of resume fraud from significant others. However, given the high rate of education discrepancies identified among Hong Kong applicants, it is possible that the social norms perceived by job applicants are permissive instead of disapproving. Future research should include an additional conception of social norms to test whether an expectation of tolerance or approval from significant others may encourage resume fraud intention.

Third, the results of the present study were generated from a sample comprising potential fresh graduates as respondents. Cautious interpretation is required when the results are used to predict the behavioral intention of working employees applying for new jobs. Due to their exposure to work cultures working employees may have developed different considerations and subjective norms that are different from fresh graduates. Future studies may consider testing the hypotheses on other samples of working employees.

\section{Acknowledgement}

This research was supported by a research grant from UOW College Hong Kong under grant 003/FBU/2019. We thank our colleagues from the Faculty of Business and Faculty of Social Sciences of the College who assisted in the data collection of the research. 


\section{References}

Ajzen, I. (1985). From intentions to actions: A theory of planned behaviors. In J. Kuhl \& J. Beckmann (Eds.), Action-control: From cognition to behavior (pp. 11-40). Heidelberg, Germany: Springer. https://doi.org/10.1007/978-3-642-69746-3_2

Ajzen, I. (1991). The theory of planned behavior. Organizational Behavior and Human Decision Processes, 50(2), 179-211. https://doi.org/10.1016/0749-5978(91)90020-T

Ajzen, I., \& Fishbein, M. (1969). The prediction of behavioral intentions in a choice situation. Journal of Experimental Social Psychology, 5(4), 400-416. https://doi.org/10.1016/0022-1031(69)90033-X

Ajzen, I., \& Fishbein, M. (1970). The prediction of behavior from attitudinal and normative variables. Journal of Experimental Social Psychology, 6(4), 466-487. https://doi.org/10.1016/0022-1031(70)90057-0

Ajzen, I., \& Fishbein, M. (1980). Understanding Attitudes and Predicting Social Behavior. Englewood Cliff, NJ: Prentice-Hall.

Bachman, R., Paternoster, R., \& Ward, S. (1992). The rationality of sexual offending: Testing a deterrence/rational choice conception of sexual assault. Law and Society Review, 26, 343-372. https://doi.org/10.2307/3053901

Beccaria, C. (1963, Original work published 1764). On crimes and punishments (introduction by H. Paolucci, Trans.). New York: Macmillan.

Becker, G. S. (1968). Crime and punishment: an economic approach. The Journal of Political Economy, 76(2), 169-217. https://doi.org/10.1086/259394

Bible, J. D. (2012). Lies and damned lies: Some legal implications of resume fraud and advice for preventing it. Employee Relations Law Journal, 38, 22-47.

Biel, A., \& Thoegersen, J. (2007). Activation of social norms in social dilemma: A review of the evidence and reflections on the implications for environmental behavior. Journal of Economic Psychology, 28(1), 96-112. https://doi.org/10.1016/j.joep.2006.03.003

Black, J. S., Stern, P. C., \& Elworth, J. T. (1985). Personal and contextual influences on household energy adaptations. Journal of Applied Psychology, 70(1), 3-21. https://doi.org/10.1037/0021-9010.70.1.3

Botetzagias, I., Dima, A.-F., \& Malesios, C. (2015). Extending the theory of planned behavior in the context of recycling: The role of moral norms and of demographic predictors. Resources, Conservation and Recycling, 58-67. https://doi.org/10.1016/j.resconrec.2014.12.004

Clarke, R., \& Cornish, D. B. (1985). Modelling offenders' decisions: A framework for research and policy. In T. Michael \& N. Morris (Eds.), Crime and justice. An annual review of research (vol. 6, pp. 147-185). Chicago, IL: The University of Chicago Press. https://doi.org/10.1086/449106 
Clarke, R. V. (1992). Introduction. In R. V. Clarke (Ed.), Situational crime prevention. Successful case studies (pp. 3-36). New York: Harrow \& Heston.

Clarke, R. V. (2014). Affect and the reasoning criminal: past and future. In J. L. Van Gelder, H. Elffers, D. Reynald \& D. Nagin (Eds.), Affect and cognition in criminal decision-making (pp. 20-41). London, England: Routledge.

Cornish, D. B., \& Clarke, R. V. (1987). Understanding crime displacement: An application of rational choice theory. Criminology, 25(4), 933-947. https://doi.org/10.1111/j.1745-9125.1987.tb00826.x

Cromwell, P., Parker, L., \& Mobley, S. (2003). The five-finger discount: An analysis of motivations for shoplifting. In P. Cromwell (Ed.), In their own words: Criminals on crime (pp. 113-125). Los Angeles, CA: Roxbury Publishing.

Curtis, G. J., Cowcher, E., Greene, B. R., Rundle, K., Paull, M., \& Davis, M. C. (2018). Self-control, injunctive norms, and descriptive norms predict engagement in plagiarism in a Theory of Planned Behavior Model. Journal of Academic Ethics, 16(3), 225-239. https://doi.org/10.1007/s10805-018-9309-2

Dahlbäck, O. (2003). Analyzing rational crime-models and methods. Dordrecht, Netherlands: Kluwer. https://doi.org/10.1007/978-94-017-0721-3

Dawson, J. F. (2014). Moderation in management research: What, why, when, and how. Journal of Business Psychology, 29(1), 1-19. https://doi.org/10.1007/s10869-013-9308-7

De Haan, W., \& Vos, J. (2003). A crying shame: The over-rationalized conception of man in the rational choice perspective. Theoretical Criminology, 7(1), 29-54. https://doi.org/10.1177/1362480603007001199

Dhami, M. K., \& Mandel, D. R. (2012). Crime as risk taking. Psychology, Crime \& Law, 18(4), 389-403. https://doi.org/10.1080/1068316X.2010.498423

Donovan, J. J., Dwight, S. A., \& Hurtz, G. M. (2003). An assessment of the prevalence, severity, and verifiability of entry-level applicant faking using the randomized response technique. Human Performance, 16(1), 81-106. https://doi.org/10.1207/S15327043HUP1601_4

Doran, R., \& Larsen, S. (2016). The relative importance of social and personal norms in explaining intentions to choose eco-friendly travel options. International Journal of Tourism Research, 18(2), 159-166. https://doi.org/10.1002/jtr.2042

Etzioni, A. (1988). The moral dimension: Towards a new economics. New York: The Free Press.

Foglia, W. D. (1997). Perceptual deterrence and the mediating effect of internalized norms among inner-city teenagers. Journal of Research in Crime and Delinquency, 34(4), 414-442. https://doi.org/10.1177/0022427897034004002

Fontaine, R. G., Fida, R., Paciello, M., Tisak, M. S., \& Caprara, G. V. (2012). The mediating 
role of moral disengagement in the developmental course from peer rejection in adolescence to crime in early adulthood. Psychology, Crime \& Law, 20(1), 1-19. https://doi.org/10.1080/1068316X.2012.719622

Fornara, F., Carrus, G., Passafaro, P., \& Bonnes, M. (2011). Distinguishing the sources of normative influence on pro-environmental behaviors: The role of local norms in household waste recycling. Group Process and Intergroup Relations, 14(5), 623-635. https://doi.org/10.1177/1368430211408149

Gudjonsson, G. H. (2016). Hans Eysenck's theory on the 'causes' and 'cures' of criminality: A personal reflection. Personality and Individual Differences, 103, 105-112. https://doi.org/10.1016/j.paid.2016.04.030

Haar, D.-H., \& Wikström, P.-O. H. (2010). Crime propensity, criminogenic exposure and violent scenario responses: Testing situational action theory in regression and Rasch models. European Journal of Applied Mathematics, 21(4-5), 307-323. https://doi.org/10.1017/S0956792510000161

Henle, C. A., Dineen, B. R., \& Duffy, M. K. (2019). Assessing intentional resume deception: Development and nomological network of a resume fraud measure. Journal of Business Psychology, 34, 87-106. https://doi.org/10.1007/s10869-017-9527-4

Higgins, G. E. (2007). Digital piracy, self-control theory, and rational choice: An examination of the role of value. International Journal of Cyber Criminology, 1(1), 33-55. https://doi.org/10.5281/ZENODO.18277

HireRight. (2017). 2017 Employment screening benchmark report. Retrieved from https://www.hireright.com/benchmarking

HireRight. (2019). Resume discrepancies in decline as APAC businesses up their efforts to screen candidates. Retrieved from https:/www.hireright.com/apac/news/press-release/apac-2017-2018-candidate-discrepancy-s potlight

Hopper, J. R., \& Nielsen, J. M. (1991). Recycling as altruistic behavior. Normative and behavioral strategies to expand participation in a community recycling program. Environment and Behavior, 23(2), 195-220. https://doi.org/10.1177/0013916591232004

Kahneman, D., \& Frederick, S. (2004). Attribute substitution in intuitive judgment. In M. Augier \& J. G. March (Eds.), Models of a man: Essays in memory of Herbert A. Simon (pp. 411-432). Cambridge, MA: MIT Press.

Kim, B. H. (2011). Deception and applicant faking: Putting the pieces together. In G. P. Hodgkinson \& J. I. Ford (Eds.), International review of industrial and organizational psychology (vol. 26, pp. 239-292). Chichester, West Sussex: Wiley. https://doi.org/10.1002/9781118311141.ch7

Kroneberg, C., Heintze, I., \& Mehlkop, G. (2010). The interplay of moral norms and instrumental incentives in crime causation. Criminology, 48(1), 259-294. 
https://doi.org/10.1111/j.1745-9125.2010.00187.x

Liao, C., Lin, H.-N., \& Liu, Y.-P. (2010). Predicting the use of pirated software: A contingency model integrating perceived risk with the theory of planned behavior. Journal of Business Ethics, 91(2), 237-252. https://doi.org/10.1007/s10551-009-0081-5

Matsueda, R. L., Kreager, D. A., \& Huizinga, D. (2006). Deterring delinquents: A rational choice model of theft and violence. American Sociological Review, 71(1), 95-122. https://doi.org/10.1177/000312240607100105

McDaniel, M. A., Douglas, E. F., \& Snell, A. F. (1997). A survey of deception among job seekers. In G. J. Lautenschlager (Chair), Faking on non-cognitive measures: The extent, impact, and identification of assimilation. Symposium conducted at the 12 th annual conference of the Society for Industrial and Organizational Psychology. St. Louis, MO.

Mehlkop, G., \& Graeff, P. (2010). Modelling a rational choice theory of criminal action: Subjective expected utilities, norms, and interactions. Rationality and Society, 22(2), 189-222. https://doi.org/10.1177/1043463110364730

Norman, P. (2011). The theory of planned behavior and binge drinking among undergraduate students: Assessing the impact of habit strength. Addictive Behaviors, 36(5), 502-507. https://doi.org/10.1016/j.addbeh.2011.01.025

Parsons, J. T., Halkitis, P. N., Bimbi, D., \& Borkowski, T. (2000) Perceptions of the benefits and costs associated with condom use and unprotected sex among late adolescent college students. Journal of Adolescence, 23(4), 377-391. https://doi.org/10.1006/jado.2000.0326

Parsons, J. T., Siegel, A. W., \& Cousins, J. H. (1997). Late adolescent risk-taking: Effects of perceived benefits and perceived risks on behavioral intentions and behavioral change. Journal of Adolescence, 20(4), 381-392. https://doi.org/10.1006/jado.1997.0094

Paternoster, R., \& Simpson, S. (1996). Sanction threats and appeals to morality: Testing a rational choice model of corporate crime. Law \& Society Review, 30(3), 549-584. https://doi.org/10.2307/3054128

Pogarsky, G., Piquero, A. R., \& Paternoster, R. (2004). Modeling change in perceptions about sanction threats: The neglected linkage in deterrence theory. Journal of Quantitative Criminology, 20(4), 343-369. https://doi.org/10.1007/s10940-004-5868-z

Prospects. (2017). Advice and guidance on degree fraud: A toolkit for employers. Manchester, UK: Higher Education Careers Services Unit (HECSU).

Schwartz, S. H. (1977). Normative influences on altruism. In L. Berkowitz (Ed.), Advances in experimental social psychology (Vol. 10, pp. 221-279). New York: Academic Press. https://doi.org/10.1016/S0065-2601(08)60358-5

Shah, A. K., \& Oppenheimer, D. M. (2008). Heuristics made easy: An effort-reduction framework. Psychological Bulletin, 207-222. https://doi.org/10.1037/0033-2909.134.2.207 
Shover, N., \& Hochstetler, A. (2005). Choosing white-collar crime. Cambridge, MA: Cambridge University Press. https://doi.org/10.1017/CBO9780511803482

Simon, H. A. (1957). Administrative behavior: A study of decision-making processes in administrative organization (2nd ed.). New York: Macmillan. https://doi.org/10.2307/2390693

Skrzypiec, G. (2017) Adolescents' intentions to engage in criminal activity: A cross-disciplinary approach linking theories from social psychology and criminology. Journal of Forensic Psychology Research and Practice, 17(5), 305-337, https://doi.org/10.1080/24732850.2017.1374720

Stone, T. H., Jawahar, I. M., \& Kisamore, J. L. (2009). Using the theory of planned behavior and cheating justifications to predict academic misconduct. Career Development International, 14(3), 221-241. https://doi.org/10.1108/13620430910966415

Synyak, K. (2014). Exploring relationships between resume fraud and individual differences. Unpublished master's dissertation, The University of Western Ontario, Canada.

Tibbetts, S. G., \& Myers, D. L. (1999). Low self-control, rational choice, and student test cheating. American Journal of Criminal Justice, 23(2), 179-200. https://doi.org/10.1007/BF02887271

Tittle, C. R., Antonaccio, O., Botchkovar, E., \& Kranidioti, M. (2010). Expected utility, self-control, morality, and criminal probability. Social Science Research, 39(6), 1029-1046. https://doi.org/10.1016/j.ssresearch.2010.08.007

Van Gelder, J. L. (2013). Beyond rational choice: the hot/cool perspective of criminal decision making. Psychology, Crime \& Law, 19(9), 745-763. https://doi.org/10.1080/1068316X.2012.660153

Walters, G. D. (2015). The decision to commit crime: Rational or nonrational? Criminology, Criminal Justice Law, and Society, 16(3), 1-18. https://doi.org/10.21202/1993-047X.10.2016.3.252-270

Wenzel, M. (2004). The Social side of sanctions: Personal and social norms as moderators of deterrence. Law and Hum Behavior, 28(5), 547-567. https://doi.org/10.1023/B:LAHU.0000046433.57588.71

White, K. M., Smith, J. R., Terry, D. J., Greenslade, J. H., \& McKimmie, B. M. (2009). Social influence in the theory of planned behavior: the role of descriptive, injunctive and in-group norms. British Journal of Social Psychology, 48(1), 135-158. https://doi.org/10.1348/014466608X295207

Wikström, P. O. (2004). Crime as alternative. Towards a cross-level situational action theory of crime causation. In J. McCord (Ed.), Beyond empiricism: institutions and intentions in the study of crime. Advances in criminological theory (pp. 1-37). New Brunswick, NY: Transaction. https://doi.org/10.4324/9781351322560-1 


\section{Macrothink}

Wood, J. L., Schmidtke, J. M., \& Decker, D. L. (2007). Lying on job applications: The effects of job relevance, commission, and human resource management experience. Journal of Business Psychology, 22(1), 1-9. https://doi.org/10.1007/s10869-007-9048-7

Wright, V. (2010). Deterrence in criminal justice: Evaluating certainty vs. severity of punishment. DC: The Sentencing Project.

Yoon, C. (2010). Theory of planned behavior and ethics theory in digital piracy: An integrated model. Journal of Business Ethics, 100, 405-417. https://doi.org/10.1007/s10551-010-0687-7

Zinatmotlagh, F., Ataee, M., Jalilian, F., Mirzaeialavijeh, M., Aghaei, A., \& Shirazi, K. K. (2013). Predicting aggression among male adolescents: An application of the theory of planned behavior. Health Promotion Perspectives, 3(2), 269-275. https://doi.org/10.5681/hpp.2013.031

\section{Copyrights}

Copyright for this article is retained by the author(s), with first publication rights granted to the journal.

This is an open-access article distributed under the terms and conditions of the Creative Commons Attribution license (http://creativecommons.org/licenses/by/4.0/). 